\title{
La estética del fragmento en la prosa modernista y su transformación contemporánea
}

\author{
The Aesthetics of Fragment in the Modernist Prose \\ and its Contemporary Transformation
}

A estética do fragmento na prosa modernista e sua transformação contemporânea

\section{Karl Erik Schøllhammer}

PONTIFÍCIA UNIVERSIDADE CATÓLICA DO RIO DE JANEIRO, BRASIL

Profesor del Departamento de Letras de la Pontifícia Universidade

Católica do Rio de Janeiro. Doctor en Literatura de la Universidad

de Aarhus, Dinamarca. Ha publicado Além do visível: o olhar

da literatura (7 Letras, 2007), Ficção brasileña contemporânea

(Civilização Brasileña, 2009), Cena do crime (Civilização Brasileira,

2013). Correo electrónico: karlerikschollhammer@me.com

Artículo de reflexión

Este artículo forma parte del proyecto de investigación del Conselho Nacional de Desenvolvimento Científico e Tecnológico (CNPq): "Realismo afetivo: evocar realidade além da representação".

Traducción de Maria Cândida Ferreira de Almeida y María de los Ángeles Aldana (graduada de Literatura y Filosofía de la Universidad de los Andes, Bogotá; correo electrónico: md.aldana57@uniandes.edu.co)

Documento accesible en línea desde la siguiente dirección: http://revistas.javeriana.edu.co 


\section{Resumen}

Este ensayo busca establecer una comparación entre las temporalidades modernista y contemporánea, para luego distinguir dos estéticas diferenciadas del fragmento en la prosa literaria. El argumento pasa por un contraste del término simultaneidad y la discusión de la idea de una escritura "cinematográfica" en la perspectiva del tiempo y del espacio. Así, a partir del análisis del fragmento en cada caso, se pueden comprender las características de la prosa en cada época, correspondientes a estéticas con enfoques y objetivos distintos, aunque no inconexos.

Palabras clave: fragmento, prosa, escritura, modernidad, contemporaneidad, Brasil. Palabras descriptor: Prosa, modernismo (Literatura), escritura, Brasil.

\section{Abstract}

This essay aims to establish a comparison between the modernist and contemporary temporalities and then distinguish two distinct aesthetic of the fragment in literary prose. The argument goes through a contrast of the term simultaneity and the discussion of the idea of writing "cinematographic" in the perspective of time and space. Thus, from the analysis of the fragment in each case, you can understand the characteristics of prose in every age, corresponding to aesthetics with different approaches and objectives, although not unrelated.

Keywords: fragment, prose, writing, modernity, contemporaneity, Brazil. Keywords plus: Prose literatura, Modernism (Literature), writing, Brazil.

\section{Resumo}

Este ensaio busca estabelecer uma comparação entre as temporalidades modernista e contemporânea, para distinguir duas estéticas diferenciadas do fragmento na prosa literária. $\mathrm{O}$ argumento passa por um contraste do termo "simultaneidade" e a discussão da ideia de uma escritura "cinematográfica" na perspectiva do tempo e do espaço. Assim, a partir da análise do fragmento em cada caso, se podem compreender as características da prosa em cada época, correspondentes a estéticas com enfoques e objetivos distintos, mesmo não inconexos.

Palavras-chaves: fragmento, prosa, escritura, modernidade, contemporaneidade, Brasil.

Palavras-chave descritores:

Prosa, Modernismo (Literatura), escrita, Brasil.

\section{Cómo citar este artículo:}

Schøllhammer, Karl Erik. "La estética del fragmento en la prosa modernista y su transformación contemporánea". Cuadernos de Literatura 18.35 (2014): 189-197. 
EL PROSISTA MÁS destacado del movimiento modernista brasileño fue, sin duda, Oswald de Andrade, principalmente en los libros Memórias sentimentais de foão Miramar, de 1924, y el Serafim Ponte Grande, escrito en 1929 y editado hasta 1934. Hoy Oswald es recordado especialmente por los manifiestos programáticos del modernismo, el "Manifiesto de palo Brasil" y el "Manifiesto antropófago", cuya escritura también presenta características de texto fragmentado, aunque dentro del estilo de los manifiestos de vanguardia tan elocuentemente determinado por Marinetti, entre otros. También son recordados los innumerables ensayos y textos críticos, y no es poco común que se olvide la obra en prosa que contiene varios títulos, entre ellos, las novelas más tradicionales Os condenados (1922), $A$ estrela de absinto (1927), A escada vermelha (1934) y, finalmente, Marco zero: a revoluçao melancólica (1943), cuya lectura hoy resulta bastante aburrida, al no tener la energía creativa de los dos libros experimentales mencionados. Es Antonio Candido quien primero marca esa diferencia cuando observa acertadamente esa nueva fase de la escritura oswaldiana:

Todo es diferente, desde el lenguaje, desnudo e incisivo, todo concentrado en la sátira social, hasta perder la pretensión de actitud literaria, pues no se preocupa por embellecer la vida. Se opone ferozmente a la primera ifase?, con un tono masculino de revuelta, sátira, demolición, subversión de todos los valores, delineado en las admirables Memórias sentimentais de foão Miramar y culminado en el fragmento del gran libro que es el Serafim Ponte Grande. (37)

Desde el punto de vista de la historia del modernismo, la novela que siempre ha destacado de la primera generación es Macunaíma, que Mário de Andrade escribió en 1929 y que, por la proximidad que tiene en cuanto propuesta, narrativa y realización con los tópicos desarrollados en el "Manifiesto antropófago", terminó por ser canonizada dentro de cierta lectura nacionalista como la novela modernista brasileña por excelencia. Por su parte, los dos libros de Oswald que tratan de una burguesía paulista cosmopolita son en estilo los que más se aproximan a los géneros de novela de costumbre satírica y novela de viaje autobiográfica, por lo que es fácil notar que la identificación con el movimiento en su radicalidad ideológica no era tan evidente. Hoy, sin embargo, las obras de Oswald obtienen nuevo interés por características que a continuación serán discutidas y que, en una perspectiva internacional, sitúa estos libros entre las experiencias modernistas más importantes. Luego, trato de señalar las preguntas que surgen del uso particular del fragmento de la novela Memórias sentimentais de foão Miramar para pensar la posibilidad de entender este recurso en sus diferencias históricas. 
En el caso del Memórias sentimentais de foão Miramar, la estructura es formada por 163 fragmentos bastante breves, en su mayor parte de pocas líneas y siempre menores de una página. Los fragmentos textuales son presentados gráficamente de modo que unas veces recuerdan poemas, y otras los textos cortos, aforismos o minicuentos. Cada fragmento tiene una cierta autonomía y mantiene siempre una reminiscencia de una historia en curso, no obstante, soltando las rigurosas marcas temporales así como las concatenaciones causales de la trama. En lugar de una linealidad secuencial, los fragmentos forman una colcha de retazos que posibilitan conexiones complejas y múltiples, creando y crean la sensación de una tela tridimensional y cierta ilusión de espacialidad. El estilo es híbrido en el sentido en que transgrede las claras diferencias entre las formas literarias, y también porque incorpora y juega con formatos aparentemente no ficcionales como misivas, citas, diálogos, fórmulas (invitaciones, anuncios, cartas de negocio), anotaciones, impresiones, relatos de viaje, tarjetas postales, entre otros. Hay una secuencia narrativa biográfica, pero la fuerza del libro no está tanto en la historia que narra sino en lo que Haroldo de Campos llamó su estilo telegráfico y en el uso de la metáfora lancinante. Si hubiera alguna semejanza con algo reconocible sería con una especie de diario sentimental lleno de registros y anotaciones de los eventos ínfimos de una sociedad ociosa y provinciana. Su tono es de parodia y su presentación ofrece la posibilidad de que sea leído sin la secuencia lineal, como una colcha de retazos, un collage de fragmentos agrupados de una manera llamada por Hugo Friedrich prosa contrapuntual. Esta prosa destruye la oración como fundamento sintáctico al dejar los fragmentos uno al lado del otro, en yuxtaposición discontinua, y eliminar la unión secuencial de la construcción gramatical común. De esta manera, un primer efecto es el desdoblamiento de la linealidad temporal en una multiplicidad de "líneas" paralelas que ofrece la progresión simultánea de diferentes "tiempos". Haroldo de Campos llamó a ese desdoblamiento un estilo cinematográfico, por su característica similar al montaje paralelo de varias historias que ocurren al mismo tiempo sin jerarquía necesaria. Lo mismo sucede en el recurso del flujo de conciencia", por ejemplo en las novelas clásicas modernistas de Virginia Woolf y James Joyce. En la poética modernista de Mário de Andrade, formulada en el libro A escrava que nao é Isaura, el autor habla de una estructura en la que "varias ramas se entrelazan en lo que generalmente se llama de SIMULTANEIDAD" (265). Ese recurso en la poesía gana el rótulo de simultaneísmo, y aunque describe principalmente la pluralidad de voces, también llamada polifonía, se trata de un desdoblamiento que indica la ambición moderna de realización plural y plena del arte en una sinestesia que Mário ya 
percibe en la música del siglo XVIII y que sintetiza en la siguiente frase: "LA OBRA DE ARTE es una MÁQUINA DE PRODUCIR CONMOCIONES" (258).

La comprensión del arte como una máquina capaz de crear afectos y sensaciones suena contemporánea y se vincula enseguida con lo que Mário de Andrade denomina cinetografía (258). Mário exalta la cinetografía como la gran traducción tecnológica de las aspiraciones expresivas de las artes plásticas y de la palabra, "realizando la vida como ningún arte aún conseguirá, el ¡Eureka! de las artes puras" (258). Mário de Andrade no fue el único ni el primero en resaltar este privilegio del cine. El historiador de arte marxista Arnold Hauser caracterizó el alto modernismo como la época del cine, justamente por la capacidad técnica de expresar una nueva experiencia histórica del entrelazamiento entre tiempo y espacio. Como Mário de Andrade, Hauser percibe en la cinetografía la superación de la naturaleza estática de la imagen plástica y de la fotográfica. La imagen en movimiento en la gran pantalla favorecía la concretud del tiempo histórico como movimiento sucesivo y continuo, y simultáneamente heterogéneo y discontinuo. El descubrimiento del montaje paralelo y del primer plano por Griffith y Eisenstein permitió, según Hauser, la expresión directa de simultaneidad y yuxtaposición que hicieron posibles la integración entre épocas; entre estados de conciencia; entre el pasado de la memoria, el presente de la percepción y el futuro del deseo; entre enredos paralelos y entre experiencia e imaginación. De modo que el cine, en vez de limitarse a representar contenidos históricos y culturales, ofrecía de forma concreta la experiencia histórica de la tendencia de fragmentación, de heterogeneidad y de desintegración del mundo moderno. Así mismo, creó una nueva unidad -sustentada materialmente por la película del cine- eminentemente perceptible detrás del ritmo caótico de la imagen caleidoscópica que aludía al flujo infinito y continuo de la experiencia interior del tiempo cualitativo, descrito por Henri Bergson como duración (durée).

El privilegio de la tecnología cinematográfica, considerada la máxima expresión de la sensibilidad estética sobre la condición moderna, reside así en la capacidad concreta de poder figurar un cambio histórico en la relación fenomenológica entre sujeto, espacio y tiempo. El cine conseguía, para los primeros críticos, concretar la disolución del espacio homogéneo y tridimensional del perspectivismo renacentista y cartesiano, a través de la relatividad, de la heterogeneidad y de la fragmentación; del espacio histórico representado por el alto modernismo. De modo ejemplar, desde esta perspectiva el cine no representa, sino que crea una expresión concreta - de la permeabilidad entre el espacio interior de la imaginación y el espacio exterior de la experiencia-. En este sentido, el cine acompaña la liberación -buscada por las artes plásticas- de 
la hegemonía figurativa del realismo. Sin embargo, la mayor cualidad de la imagen cinematográfica es el descubrimiento del movimiento como manifestación concreta de la temporalidad histórica. El tiempo pierde en el cine su irreversibilidad cronológica por las retrospecciones, repeticiones, recuerdos y visiones premonitoras, y la imagen en movimiento posibilita relaciones simultáneas entre acontecimientos alejados, historias paralelas y experiencias desenlazadas en el espacio y en el tiempo. Es el descubrimiento fascinante, dijo Hauser, de que "por un lado, el mismo hombre experimenta muchas cosas diferentes, desenlazadas e inconciliables en un mismo momento, y, por otro, hombres diferentes en lugares diferentes experimentan muchas veces las mismas cosas" (1135).

En esta perspectiva, la paradoja de la representación cinematográfica consiste en dar concretud a la fragmentación del mundo moderno y, simultáneamente, ofrecer una unidad material y sensible a un tejido singular de relaciones, conexiones y a las afinidades entre experiencias múltiples que apuntan a una nueva dimensión cualitativa del tiempo. La inspiración en la plasticidad de la expresión cinematográfica se convirtió en un fundamento para los modernistas brasileños de los años veinte, en particular para Mário de Andrade y Oswald de Andrade. Basta recordar que Mário caracterizó su propia novela Amar, verbo intransitivo como novela cinematográfica. En el caso de Oswald, la inspiración se hace evidente en Memórias sentimentais de foão Miramar, no solo por el estilo recortado y plural, sino también por la referencia narrativa al cine como una tecnología moderna que les interesa a los personajes.

Haroldo de Campos explora en el ensayo "Miramar en la mira" la idea de una prosa cinematográfica por la aproximación a dos aspectos de la conciencia cinematográfica que siguen siendo importantes en el desarrollo de la literatura en la época actual: la complejidad que adquiere la estructura narrativa y la nueva cualidad sensible de la superficie textual. La influencia del cine sobre la prosa modernista confirmaba el fin de la narrativa tradicional y su organización en tramas fuertes, pues la nueva coherencia dada por la película a la experiencia heterogénea de la realidad eximía el engranaje de la acción narrativa.

Arnold Hauser describe, por ejemplo, el desempeño del cine sobre la ficción como la posibilidad de abandonar la trama fuerte y eliminar al héroe clásico moderno, así como sus motivaciones psicológicas. El modernismo literario se inspiraba en la combinación de formas temporales y espaciales, y desplegaba métodos automáticos de escritura y nuevas técnicas de montaje que interrumpen la linealidad narrativa tradicional, al introducir nuevas fuerzas dinámicas de desarrollo. Para Hauser, estas apuntaban a la superación definitiva de la trama aristotélica. La palabra clave en la definición de ese nuevo concepto de tiempo 
era simultaneidad -o simultaneísmo-, que en el cine se expresaba directamente en el entrelazamiento entre tiempo y espacio, en la simultánea espacialización del tiempo y temporalización del espacio. Pero ese mismo entrelazamiento entre espacio y tiempo, reconocido en la física de la relatividad y llamado por Einstein space-time, había motivado a identificar en esa literatura una especie de "novela espacial" o la temporalidad que, en detrimento del espacio, ganaría una nueva cualidad existencial por detrás de la cronología histórica. De la misma manera que la cualidad artística del cine fue vista en la posguerra en función de su capacidad para expresar el tiempo vivo como venir-a-ser fenomenal en la dinámica de las relaciones entre personajes y circunstancias, en detrimento de la fuerza narrativa del cine comercial "hollywoodiano", el futuro de la novela era previsto como un abandono de la construcción de tramas fuertes y el predominio del descubrimiento de una nueva cualidad sensible de la superficie textual. En vez de la estructura narrativa como fundamento dinámico de la novela, el nouveau roman (Orr) revelaba en el tejido textual y en la riqueza descriptiva la manifestación compleja de experiencias y afectos entre una subjetividad en disolución pulsional y un mundo fragmentado y multifacético.

Desde el punto de vista contemporáneo, existen en la percepción modernista de la simultaneidad indicadores de algo que retrospectivamente podemos ver que anticipa la característica del cronotopo posmoderno/contemporáneo y otro sentido de lo simultáneo. Si el modernismo de las primeras décadas del siglo XX anunciaba una profundización de la crisis del historicismo moderno, cuyos zócalos principales eran la cronología temporal y la secuencia narrativa, la época actual introdujo otro sentido de lo simultáneo inmanente en el concepto propuesto por Hans Ulrich Gumbrecht de un presente amplio (2012). Según el análisis de Gumbrecht, el presente es amplio en la medida en que posibilita un anacronismo deliberado entre pasado, presente y futuro, en el que el pasado aparentemente se vuelve insuperable y el futuro inaccesible o una amenaza latente. En ese sentido, el pasado en el contemporáneo se acumula sin cesar y amarrado a la vez a su herencia. Es archivo y futuro, y no ofrece ninguna expectativa de liberación. El presente amplio es la convivencia simultánea del pasado, el presente y el futuro en una especie de parálisis poshistórica o poshistoricista, al mismo tiempo que convive con el historicismo, ya que representa su secuencia y continuidad. En el auge del modernismo se planteaba la pregunta sobre la temporalidad del cronotopo historicista caracterizado, según Gumbrecht, por cuatro factores: el historicismo ofrece una narrativización que explicaba la inestabilidad representativa de los fenómenos históricamente, el ancla de la superación de la crisis de la representación era el sujeto histórico individualizante y existencia,; el tiempo era 
percibido como el agente absoluto de transición, y el presente temporal ganaría el privilegio de convertirse en el medio de transición que sugiriera la duración intrínseca del tiempo cualitativo.

Para el cronotopo contemporáneo, por su parte, el principal tópico es el presente amplio, sin futuro promisor ni pasado superable. La simultaneidad se configura en la yuxtaposición de pasado-presente-futuro, diferente de la simultaneidad modernista de las acciones. En lugar de la autorreferencia cartesiana (subjetivismo), el presente amplio se sustenta en la autorreferencia corporal y material, además de la transformación y el desarrollo histórico substituido por el estancamiento. Si consideramos el fragmento en el contexto modernista como el índice de un paradigma historicista sustentado en la temporalidad narrativa, cuya transcendencia es evocada en la utopía de la duración, el cronotopo contemporáneo indica una constelación espacial entre momentos narrativos discontinuos -del pasado, presente y futuro-. Estos interactúan y se tensionan por conexiones no necesariamente narrativas, en el sentido de secuencias movidas por causa y efecto. En la comprensión de la simultaneidad del cronotopo contemporáneo, a diferencia de la simultaneidad modernista, es importante tener en mente que no se trata de una superación del cronotopo historicista, algo que afirmaría ese mismo cronotopo, sino de una supervivencia del historicismo dentro del contemporáneo. Entonces, se trata de una simultaneidad gradual entre dos cronotopos. Esto significa que el aspecto cinematográfico en el contemporáneo aparece, por ejemplo, en la secuencia discontinua de planos secuencia en los que cada plano fragmentario contiene un germen narrativo, sin que exista un desarrollo temporal entre los planos configurados en constelaciones complejas y espaciales.

La relación entre el cronotopo historicista y el contemporáneo se corresponde con la comparación posible entre dos estéticas del fragmento. La primera es elaborada desde el joven romanticismo, en el que el fragmento dobla el pasado residual melancólicamente y lo desdobla en el expansionismo embrionario y utópico modernista. Y otra en la que el fragmento apunta holográficamente a la relación entre la unidad material y concreta del fragmento (obra, texto, imagen, cuerpo, etc.) y su condición dinámica y rizomática en una unidad nunca configurada plenamente. El fragmento moderno es el ícono de una temporalidad promisora en su devenir, mientras que el fragmento contemporáneo lo es de la configuración espacial virtual en la que plantea volverse comprensible.

Un ejemplo es ofrecido por Fernando Bonassi en uno de los minicuentos del libro 100 Coisas (2000):

Ecos de sirenas. Voces de prisión. Gatos con ratas muertas en la boca. Ratas muertas con hormigas en la boca. Niños llorando abiertamente. Hombres- 
hechos llorando ocultos. Cubiertos rayando platos. Televisión en el fin. Alcaparras suspendidas en aceite. Rostros de terror espiando en los vidrios. Diez millones de oraciones innombrables dentro de las almohadas. Cristos de loza. Toallas plásticas. Claveles y espinas. Chatas y cuencas. Escapes aburridos, cohetes, disparos. Pilas gastadas. Ni pomada. Ni mierda. Ni droga. Ni pereza. Ni una bolsa de basura para coger. (37)

Podemos percibir cierta atemporalidad en el texto, casi exento de verbos y con un estilo fragmentario en la reducción de las frases, al mismo tiempo que su unidad substantiva. Este deja la impresión de un "texto-cosa" amarrado por elementos dispares y aislados que, entretanto, no dejan de tener sentido en su relación compleja y tridimensional. Jacques Rancière habla así de cierto cinematografismo inventado por la propia literatura y comprendido en tres vertientes específicas. La primera es el "privilegio de la palabra muda, del poder de la expresión conferida a la presencia silenciosa -significativa, enigmática o insignificante- de la cosa" (56). La segunda es la igualdad de todas las cosas representadas. La tercera vertiente es "el tratamiento secuencial del tiempo" (56). Con esto Rancière busca decir que se trata de una composición narrativa constituida por "bloques desiguales y discontinuos de espacio-tiempo, por oposición al modelo de la representación, que es la cadena temporal homogénea de causas y efectos" (56). Al soltar la progresión temporal y narrativa moderna, la literatura crea una especie de imagen-tiempo (Deleuze), es decir, un entrelazamiento del tiempo en el espacio definido, según Rancière, por dos características predominantemente espaciales: "el tropismo interno de la secuencia y el corte entre secuencias" (57). El resultado es cierta inercia, parálisis o estancamiento comprensible dentro de la elaboración del cronotopo contemporáneo y en la sensación existencial de vivir en un tiempo que se arrastra como destino en la simultaneidad entre pasado, presente y futuro, y que permite explicar el papel de los sujetos narrativos en la literatura contemporánea, su resignación y falta de voluntad de acción; su incapacidad de acción y la pérdida de identidad subjetiva, muy a pesar de su revuelta latente.

\section{Obras citadas}

Andrade, Mário de. "Escrava que não é Isaura". Obra imatura. Río de Janeiro: Agir, 2009. 2-15.

Andrade, Oswald de. Memórias sentimentais de foão Miramar. São Paulo: Globo, 1997. Bonassi, Fernando. 100 coisas. São Paulo: Angra, 2000. Campos, Haroldo. "Miramar na mira". Memórias sentimentais de foão Miramar. Por Oswald de Andrade. São Paulo: Globo, 1997. 19-6o. 
Candido, Antonio y José Aderaldo Castello. Presença da literatura brasileira: história e antologia. O modernismo. São Paulo: Bertrand Brasil, 1997.

Gumbrecht, Hans Ulrich. "Redescrições". Revista do GT-

Pragmatismo e Filosofia Americana 4.1 (2012): 36-57.

Hauser, Arnold. História social da literatura e da arte. São Paulo: Mestre Jou, 1982.

Latour, Bruno. Famais fomos modernos. Ensaio em antropologia geométrica.

Trad. Carlos Irineu da Costa. São Paulo: 34 Letras, 1994.

Orr, John. Cinema and Modernity. Cambridge: Polity Press, 1993.

Rancière, Jacques. As distâncias do cinema. Trad. Estela dos

Santos Abreu. Río de Janeiro: Contraponto, 2012. 